\title{
Minimising dietary risk: the French association of salt producers and the manufacturing of ignorance
}

\author{
Marc-Olivier.Déplaude \\ RiTME research unit, French National Institute for Agricultural Research (INRA), Ivry- \\ sur-Seine, France
}

Published in Health, Risk \& Society, vol. 17, n $^{\circ}$, p. 168-183.

\begin{abstract}
In this article I develop the social amplification of risk framework focusing on organisational strategies that seek to to minimise or conceal certain risks, rather than amplifying them. I link this analysis to theoretical work on the social production of ignorance. I draw on data from a case study of the French association of salt producers that explores the ways in which the association with limited resources sought to counteract public health messages that salt was a risk to health. I show that the association used four main strategies in an attempt to manufacture ignorance in relation to the nutritional risks of salt: indirect communication and dissimulation, denial, diversion and undermining or intimidating of opponents. I conclude that these strategies are part of a repertoire of action which is available to many industrial organisations which are trying to counteract public health claims that their products are a danger to health. I argue that it is important to integrate studies of the social amplification and attenuation of risk with analysis of the resources and strategies used to minimise or amplify risk. I suggest that the strategies used by certain powerful actors to minimise or conceal certain health or environmental risks should be analysed more closely in risk studies.
\end{abstract}

Keywords: Risk, dietary risk, social amplification of risk framework, ignorance, food industry, repertoires of collective action.

\section{Introduction}

In this article I aim to contribute to the literature on 'the social amplification of risk' (Kasperson et al., 1988). In contrast to the initial formulation of this theory and the numerous works it has inspired, my approach consists in making actors' strategies the core focus of my analysis and, more specifically, in examining how far they are 
prepared to go to minimise or conceal certain risks, and to avoid amplifying them. To broaden the application of the social amplification framework I draw on research in the field of Science and Technology Studies that has focussed in the 'social production of ignorance' (Kleinman \& Suryanarayanan, 2013). This research examines the social processes and strategies that lead to certain problems being ignored or minimised so that they are confined within limited or marginal spaces. I test this approach to the amplification of risk framework by studying the strategies employed by the French association of salt producers (Comité des Salines de France - the Comité) to counter official public health advice that French citizens should reduce their salt intake. I argue that these strategies are part of a repertoire of action available to industrial organisations which want to counteract adverse assessements of the risk posed by their products to human health.

\section{Risk, ignorance and food}

\section{The social amplification and attenuation of risk}

Kasperson and his colleagues developed the 'social amplification of risk framework' to account for their observation that:

even risk events with minor physical consequences often elicit strong public concern and produce extraordinarily severe social impacts, at levels unanticipated by conventional risk analysis' (Kasperson et al., 1988, p. 177).

Drawing on communication theories, Kasperson and his colleagues suggested that an initial risk signal is modified every time it moves from one receiver/transmitter to another, and that being diffused in this manner, it can be amplified or reduced. They noted that the mass media played an important role in this process, as did certain organisations such as 'multinational corporations, business associations, and government agencies' (Kasperson \& Kasperson, 1996, p. 98). They argued that the ways in which risk assessment was modified depended on the properties of each of these social different spheres. For example:

Large corporations develop markedly different kinds of organizational cultures that shape powerfully their ability to identify and assess the risks of their activities and products and to determine if and how the risks will be communicated to other social institutions and publics. (Kasperson \& Kasperson, 1996, p. 98)

Proponents of this framework argued that these processes can have a very significant economic impact on certain sectors of activity, and cause certain products or technologies to be lastingly stigmatised in the public space.

This theory has been very influential in risk studies and a number of risk researchers have used it to explore the ways in which risk assessments are modified and in particular the role of the media in such changes (Henderson et al., 2014). Some of these researchers have also examined the logic underpinning the ways in which public and private agencies respond to and shape risk assessments as they attempt to predict 
people's reactions or to avoid blame and the ways in which this can influence the amplification of risk (Burgess, 2006; Torny, 2005).

However there are important limitations to the the social amplification of risk framework. Firstly, the work of Kasperson and his colleagues is based on the assumption that there is 'an external risk signal that is altered in the communication process between an initial receiver/transmitter and subsequent receivers/transmitters' (Rayner, 1988, p. 202). This implies that risk communication starts with a 'real' risk, as assessed by competent experts, which is then distorted by amplification or attenutation. And that such distortions have undesirable effects, such as 'marring and compromising the potential benefits to society from economic growth and technological change' (Kasperson \& Kasperson, 1996, p. 100). The focus of Kasperson and his colleagues is on the risk experts, policy makers and risk communication specialists, who need to accurately communicate risk information and minimise distortion with all its potentially harmful effects. Secondly, the framework focusses on the mechanic of communications, the movement of the risk message from one transmitting station to the next, and does not really explore the role of those transmitting the messages. For example, while the distorting effect of mass media is noted there is little consideration of the role of journalists and how and why they report information in the ways they do. Researchers using the amplification framework tend to explain the modification of risk messages largely in terms of cultural or structural factors and not in terms of the actions of those transmitting the messages (see Renn, 2011; Zinn, 2015). Thirdly, in both the initial conceptualisation of the framework and in the research it stimulated the emphasis has been on amplification rather than attenuation processes. This is probably because researchers have been mainly interested in issues which have been the subject of fierce public debate (genetically modified organisms, mad cow's disease, Asian flu, etc.), and in which risk has been 'amplified' rather than in risks which are ignored or rarely discussed in the public space.

In this article, I intend to deal with the limitation of the social amplification of risk framework, by taking better account of the strategies used by organisations and those working for them and of the dynamics which might lead to certain risks being minimised or concealed. Rather than analysing risk amplification or reduction as mechanical processes, I will examine strategies which aim to make certain risks more visible or, on the contrary, to conceal them. Anticipating the negative consequences that greater visibility of certain risks might have on their activities, organisations and individuals who have an economic stake in a risk assessment can make considerable efforts 'to interrupt a social amplification of risk process' (Busby et al., 2009, p. 298). For this reason, I feel it is useful to combine works from the field of risk studies with current research on the social production of ignorance.

\section{Manufacturing ignorance}

Over the last ten years there has been a growing literature on ignorance. As McGoey (2012) recently underlined, this issue is not entirely new to sociology. Several authors, from different research traditions, have looked at similar subjects, such as amnesia and forgetfulness in institutions (Douglas, 1986), the uneven circulation of information in organisations (Crozier \& Friedberg, 1980; Vaughan, 1999), the strategic uses of knowledge in public arenas (Hilgartner, 2000) or the processes of confinement and invisibilisation of certain social problems (Bachrach \& Baratz, 1962; Gilbert \& Henry, 2012). 
However, it is within the framework of Science and Technology Studies that ignorance has become the central subject of an increasing number of works, with some social scientists using a neologism, 'agnotology' (Proctor, 2008) to designate this field of research. Much of this research is concerned with the question of 'undone science' (Hess, 2007; Frickel et al., 2010), that is:

the kinds of research that get systematically left unfunded, ignored or sidelined, but [are] recognized by [other] actors as being worthy of serious consideration (Kleinman \& Suryanarayanan, 2013, p. 5).

Kleinman and Suryanarayanan tried to identify and describe the social mechanisms that explain why certain types of knowledge are not produced or are not considered worthy. They identified a number of factors:

- The specific logic of individual academic disciplines. Each discipline tends to attach importance and value to certain subjects, this means that other potentially ones are neglected by that discipline;

- The rules in force in institutional arenas of expertise. They are embedded in the protocols and instruments used in those arenas so that certain types of knowledge are systematically undervalued or disregarded (Frickel \& Edwards, 2014; Henry, 2005). For example, when studying the toxicological testing carried out in New Orleans following hurricane Katrina, Frickel and Vincent (2007) showed that said tests were not 'neutral technologies' and that they contributed towards highlighting certain types of risk and concealing others - such as those which resulted, for example, from the presence of low doses of toxins. Knowledge and ignorance are thus produced together.

- The uneven social and spatial distribution of certain health and environmental risks. Marginalised populations are very unlikely to complain about damage to their health or their environment, and thus to make broader audiences aware of them. Such risks therefore tend to be disregarded (Allen, 2003; Auyero \& Swistun, 2009; Blum, 2008).

The first group of studies, several of which can be included in the "new political sociology of science' (Frickel \& Moore, 2005), focuses on the structural and institutional mechanisms which produce ignorance, noting that the creation of such ignorance is often an unintentional result of said mechanisms. Although researchers in this first group do note that organisations and individuals with an economic stake can use the creation of ignorance to promote their interests, this is not the main focus of their research.

A second group of studies focuses on the efforts that certain actors have made to deny (or at least play down) any health or environmental risks. In studying the deliberate strategies which manufacture ignorance, these researchers have concentrated on the production of toxic substances such as tobacco (Proctor, 2011), chemicals (Markowitz \& Rosner, 2002; Ross \& Amter, 2010; Vogel, 2013) and asbestos (McCulloch \& Tweedale, 2008). McGoey (2012) coined the phrase 'strategic ignorance' to describe practices which consist in mobilising the unknowns of a given situation. Researchers who have examined this aspect of the creation of ignorance, some of whom have been interested in taking political action to uncover and denounce 
(Michaels, 2008; Oreskes \& Conway, 2010), have concentrated on collecting examples and empirical proof to support their theories. Few have tried to develop a more theoretical understanding based on systematic description and categorisation of the strategies designed to manufacture ignorance. Rayner's article (2012) is one of the rare attempts in doing this. Rayner starts by looking at how certain institutions manage what he calls 'uncomfortable knowledge', that is knowledge which might threaten the way they operate. Drawing on the anthropological works of Douglas (1966) and EvansPritchard (1940), Rayner argues that the survival of any institution or organisation relies on certain forms of knowledge being excluded:

because they threaten to undermine key organizational arrangements or the ability of institutions to pursue their goals. (Rayner, 2012, p. 108)

To avoid such a knowledge being used against them, managers in these organisations mobilise various more or less conscious strategies. Rayner identifies four types: strategies of denial, dismissal, diversion (or decoy) and displacement. Rayner defines denial as 'a refusal to acknowledge or engage with information' (Rayner, 2012, p. 113). He makes a distinction between these strategies and those of dismissal, which recognise 'the existence of information, and may involve some minimal engagement up to the point of rebutting it as erroneous or irrelevant' (Rayner, 2012, p. 113). In this article, I will adopt a broader approach and use denial to refer to both denial and dismissal as these are two alternative ways of disregarding a problem.

There are limitations of Rayner's approach. The first, which he acknowledges, is the temporary and incomplete nature of the list of strategies analysed, which as I have already noted could be grouped together differently. The other stems from his methodological approach; he builds his analysis based on examples of his experience as an expert in various public action programmes, especially in the field of the environment. This approach does not indicate how the same organisation can successively or simultaneously mobilise several types of strategy, or how the latter interconnect with one another. It is possible that these strategies are components of the same repertoire..

My aim in this article is to contribute towards the sociological study of risk, using recent works on the social production of ignorance to develop the social amplification of risk framework. But it also aims to add to this research by highlighting the existence of a repertoire of action that is common to numerous industry players.

\section{Methods}

In this article I draw on data from a case study of an association of salt manufacturers - the Comité des Salines de France. The aim of this study was to carry out an exhaustive analysis of the strategies that an association of manufacturers could use to minimise and conceal health risks relating to the activities or products of its members. As a case study design involves collecting a large volume of data on a limited subject, it enabled me to relate practices to specific social contexts and thus to adopt an interpretative understanding of social action, by carefully reconstituting the participants' strategies and reasons for acting, rather than using a priori models of behaviour (Ragin \& Becker, 1992; Yin, 2013). 
I chose to study the Comite des Salines de France, because it is a business association which has for some considerable time (more than three decades) used a wide range of strategies to try to undermine official advice about dietary salt and to promote a positive image of salt. The first stage of the study involved nine semi-structured interviews with Comité managers and with those who have had dealings with them (salt producers, experts and researchers and senior civil servants from the French Ministry of Health). These interviews gave me access to three private archives, which allowed me to gain a very precise overview of the Comités practices. To begin with, a former manager at a cooperative of salt producers allowed me to examine almost all of the Comité's annual reports from 1974 to 2008. Averaging between twenty and thirty pages, these reports provide economic and technical data on the French salt sector and on Comité's main activities for the year in question. A former senior civil servant from the French ministry of health then allowed me to consult archives pertaining to the salt industry. These archives contained various letters from the Comite to the ministry of health and to the French National Institute of Health and Medical Research . Finally, an Institute of Health researcher who was sued for defamation by the Comité in 2007, sent me the documents he had collected while preparing his defence (Comité press files and releases, letters, business reports, etc.). I made use of two other sources to complete the data from these archives: as far as possible, I collected all the articles, documents and brochures written by Comite members or with the financial or documentary support of the Comité or its members (these documents were held in various university libraries); and I went through several press documents (including the staff newsletter for Salins' French subsidiary) and various national newspapers and magazines (including some medical journals) over a period ranging roughly from the mid-1970s to now. I also transcribed all reports relating to salt which were shown on early evening news programmes or as part of specialist programmes shown on the six main national channels, and which were available for that period from the French National Institute of Audiovisual Medias.

I gathered these different sets of data to reconstitute, as fully as possible, Comité strategies aimed at different targets (doctors, journalists, teachers, general public). This was also a way of using cross-cutting sources and of convincingly recontextualizing the idealistic image that the Comité paints of itself. In the 'grounded theory' spirit (Glaser $\&$ Strauss, 1967), I inductively analysed the data to allow the emergence of an analysis which would evolve certain pre-existing theoretical frameworks. I use the Comite as an example to show how strategies which produce ignorance are part of a repertoire of action common to many industry actors; this is a new contribution to both the literature on the social amplification of risk and to the literature on the social production of ignorance.

This research was conducted in accordance with the ethical guidelines laid down by the British Sociological Association (2002). When sociologists examine controversial issues, it is sometimes difficult for them to defend certain positions without being suspected or accused of bias towards one of the parties, and thus of harming certain actors. Through the simple fact of describing certain social practices, and thus objectifying them, sociologists can harm the interests of those who would prefer to keep their actions, or the reasons for their actions, hidden from as many people as possible. Whilst it is difficult to prevent such effects, which are inherent to social science research, it is certainly possible to avoid causing harm to specific persons. In this study I have therefore been careful to maintain the anonymity of people who have not already 
been named in the public space. But even more importantly, as mentioned above, by choosing a methodology based on an interpretative understanding of social action, I was able to accurately reconstitute the reasons behind the actors' actions. As far as this research is concerned, it was not a question of separating the 'heroes' from the 'villains', but of understanding how, within a given context, the representatives of an economic sector acted to defend their own interests.

\section{Findings}

\section{A business association under challenge}

The Comité was founded in the 1920s and is a very small organisation. From the 1970s onwards it had a maximum of two permanent employees; a 'general manager' and a secretary. As salt is relatively cheap, the Comité represents a modest economic sector which employed less than 3,000 persons in the early 1980s and approximately 2,000 at the time of writing. It is dominated by the Salins group, which currently employs 1,500 people (700 in France), with a turnover of less than 300 million euros. The group mainly produces crystallised salt for human consumption (the most profitable), agriculture, gritting roads and industrial chemicals. It owns the La Baleine ${ }^{\mathrm{TM}}$ brand which it uses to market the majority of its household salt. In France the Solvay group is the second largest salt producer.It is one of the world's leading chemical groups, and it produces brine for its chemical installations, and, in lesser quantities, crystallised salt for human consumption, via Cérébos, which it bought in 1967. In 2002, Cérébos became a subsidiary of the European Salt Company (ESCO), founded by Solvay and German group $\mathrm{K}+\mathrm{S}$, and then owned by $\mathrm{K}+\mathrm{S}$ only. Salins and Solvay (then $\mathrm{K}+\mathrm{S}$ ) overwhelmingly dominate CSF's board of directors: since the beginning of the 1970s, the board has been mainly composed of Salins and Solvay executives and has always been chaired by a Salins director.

From the end of the 1970s, the Comite was facing a major challenge, with the development in France and in other western countries of new public health nutritional education campaigns stressing the need to moderate consumption of certain foodstuffs and nutrients, such as salt, which was implicated in the development of high blood pressure and cardiovascular diseases. In 1981, the Comité Français d'Education à la Santé (French committee for health education) began to promote the idea that 'healthy eating' meant having a balanced and varied diet, and 'reducing the levels of sugar, fat and salt in traditional recipes' (CFES, 1981). Consumers were encouraged not to unthinkly add salt to all of their food. The messages were widely disseminated to the general population through new communication techniques, such as audiovisual media (Berlivet, 2005). After a decline of these campaigns in the 1990s, new public health information campaigns were organised in the $2000 \mathrm{~s}$, mainly as part of the fight against obesity.

Faced with stagnating salt sales as from the end of the 1970s, the Salins group was particularly sensitive to these campaigns, especially as salt for human consumption was sold at a much higher price than that used for chemicals or gritting. Through the Comité began to make efforts to preserve salt's reputation in the fields of health and nutrition.

In 1977, the Comite decided to closely monitor the debates which were developing on how salt affects health. In 1983 it founded a 'public relations' work group made up of Salins and Solvay executives. Its purpose was to ensure that 'the image of table salt is 
not tarnished, as has notably been the case in the United States and Great Britain' (CSF, 1986).

\section{Indirect communication and self-dissimulation}

With the help of a public relations agency, the Comite decided to concentrate its efforts on three categories of professionals, who it expected to pass on its messages to a wider public: journalists, healthcare professionals and teachers. The choice of indirect communication can be interpreted in two ways. Firstly, it is less expensive than major advertising campaigns in the mainstream media. The Comité has very limited financial resources (in 2011 its annual budget was $300,000 €$ ), and its members probably prefer to allocate their advertising budgets to the promotion of their own products. This explains why over the last forty years the Comite only organised one advertising campaign on French television - in 1990-1991. Secondly, the Comite hoped that these three categories of professionals would not only relay its messages to a wider audience, but that they would also lend their strength of authority, whilst at the same time blurring and dissimulating any connection with economic interests. With the same objective in mind, in 1983 the Comité also founded a Centre de Recherche sur les Utilisations $d u$ $\mathrm{Sel}$, a centre for research on the uses of salt). In fact this research centre employs no researchers at all; it merely serves as an acronym that the Comite can use to disseminate documents which seem to be scientific, without appearing to be their author. Once again, this is a case of the Comite dissimulating or, even better, hiding its economic interests from the audiences targeted by the documents in question.

The Comité preferred method for changing journalists' opinions is to send them press kits and press releases, or to talk to them individually. To access healthcare professionals, the Comité's general manager was able to take part in congresses for dieticians and to arrange the publication of notes or articles in nutrition journals, including two in the Cahiers de Nutrition et de Diététique, a journal published by a learned society and aimed at academics and practitioners (CRUS, 1987; Moinier, 1990). Since 2008, the Comité has also been publishing a quarterly e-newsletter presenting recent scientific studies on salt and health. Finally, to influence school teachers and their pupils, the Comite offered pedagogical kits (fact sheets, slides, games) which were mainly distributed to primary and junior schools. For example, in its 1985 business report, the Comité's executive director explained:

A salt information sheet was created in 1984. It is in two parts. The first part describes the main aspects of the salt economy. The second provides educational information on salt production methods and its uses...It [this sheet] will allow primary and secondary school teachers and pupils [...] to learn about this ordinary but essential product. (CSF, 1985, p. 19).

The Comités approach was reflected in that adopted by the two major salt manufacturers, Salins and Solvay who have provided documentary or financial support for several books on the history, production techniques and uses of salt (see for example, Colas, 1985; Moinier, 1997).

The Comité used a number of techniques to enhance the impact of its 'salt is good for you' message. It used Salins' documentation department, which houses a collection of books and works on the history and uses of salt. It employed a public relations agency whose main tasks were to monitor the press, to help develop documents aimed 
at outside audiences and to ensure their effective distribution. Since 1987, the Comité has worked with medical specialist Tilman Drüeke, a nephrologist and director of a research unit in a prestigious Paris hospital. Drüeke's research led him to emphasise the complexity of the nutritional factors which caused high blood pressure and thus to put into perspective the notion that salt in food is bad for health. His research stance was in line with the Comité's interests, and it invited him to make regular summaries of medical literature on the subject of 'salt and health', to monitor work carried out by the World Health Organization and to attend medical congresses on issues of interest to salt producers. In exchange, the Comité made payments to his hospital to fund research projects.

Using such resources, the Comité managed to compile a large volume of data which it then used to deny or play down the danger of salt for health, or to divert attention away from the issue.

\section{Strategies of denial}

In my analysis of the documents developed and disseminated by the Comité I found a second set of strategies, which involved making a selective use of scientific literature and bringing into play the uncertainty evident in debates taking place within academic circles. I will refer to these as strategies of denial, their main objective being to deny the fact that salt in food is a danger to health, or, at the very least, to deny that the dangers are such that they need to be made public. Strategies of denial thus consist in denying that a given problem is a problem worthy of attention, whatever the relevant existing data may be.

In order to minimise the role that salt plays in the development of high blood pressure, the Comite argued that the salt intake of French population was lower than what was commonly stated, and that it is generally at levels with which the kidneys can cope. Furthermore, blood pressure depended on many other factors, such as excess weight or genetic predispositions. The advantage of these arguments is that they do not place responsibility for the development of high blood pressure on salt and hence on manufacturers who encourage its consumption.

However, the Comite could not deny that research existed in the danger of excess salt consumption, which have led the public health agencies to recommend that the whole French population reduced its salt intake. The Comite sought to undermine this by highlighting the uncertainty of current research and academic opinion arguing that preventive action aimed at the whole population rather than just at-risk groups was premature. The Comité. In other words, the CSF was not content to simply assert that the question of how salt affects health was subject to debate - it actually spotlighted such debates about the uncertainty of research findings. One way in which it did this was to organise counter-conferences, events that brought together French and foreign experts that were sympathetic to the Comité . For example, in March 2001, the Agence Française de Sécurité Sanitaire sur les Aliments ( the French Food Safety Agency) set up a working group to examine ways of reducing the salt content in processed foods. Its conclusions were made public by the deputy minister for health in January 2002, during an international 'salt and health' conference organised by Food Safety Agency. To counter these initiatives and muddy the water by making the case that there was no scientific consensus on the risks of eating salt the Comite organised a counterconference in September 2001, and another one the same day as the Food Safety Agency 'salt and health' conference. 
A similar approach is evident in the quarterly e-newsletter published by the Comite which from 2008 onwards has highlighted the abundance and diversity of scientific works on the links between salt and health. The repeated message in the newsletter is that the relationships between salt and health are complex, that there is on-going scientific debate that had not to date been conclusive:

'The literature monitoring carried out in early 2009 has taught us a great deal. First and foremost, it shows that the 'salt and human health' debate continues to fascinate researchers and clinicians, and that it is far from closed' (CSF, 2009, p. 1).

The Comité approach has been to maintain doubt, or, more specifically, of accomplishing a 'work of confusion' (Auyero \& Swistun, 2008) which consisted in disseminating into the public space data which was presented as being contradictory. Such confusion was maintained through the complementary use of diversion strategies.

\section{Creating diversions}

The Comité's diversionary strategies consisted in drawing attention to the benefits of salt and to the virtuous practices of the salt industry. Its 1990-1991 television campaign sought to link salt with the pleasures of eating. Commenting on the television advert, which showed a plate of vegetables which look decidedly tired until they were freshened up with a sprinkling of salt, the Comité's general manager told his members that:

It was a deliberate choice to look at salt from a pleasure standpoint, in order to reassure those who some people have been trying to make feel guilty for using the salt shaker. (CSF, 1991)

Furthermore, in the various documents the Comité distributed since the 1980s, particularly those targeting teachers and schoolchildren, it relentlessly stressed the fact that salt was a natural product and was vital to health, that salt had a long history, and through its many different uses made a major contribution towards the comfort of modern life. These arguments also underpinned the various Comité publications targeted at the general public. Whilst the publications reminded readers that they should not eat too much salt, this advice tended to be underplayed compared to the panegyric about salt's thousand-year history and the long list of its supposed benefits.

From the last 1980s, the Comite linked its narrative on the benefits of salt to the use of salt as a means of fighting deficiencies in iodine and fluorine within the French population. In 1952, public health authorities authorised salt producers to add small quantities of iodine to salt reduce the risk of goiter, a serious thyroid disorder. In 1985 the French government also authorised manufacturers to add fluoride as a means of reducing dental decay. Public health agencies considered salt as a good medium for such supplements as most of the population ate salt in small quantities.

In 1980s Salins and Solvay were already selling salt with iodine and in the late 1980s started selling salt which had both iodine and fluoride. This had a double benefit: not only was salt with iodine and fluorine more profitable it was also a way of promoting the health benefits of salt. Through the Journées Nationales de la Diététique (national diet weekly) in Marseille in 1988, the Comité's general manager set out the health 
benefits of salt with iodine and fluoride supplements. The Comite also organised publicity of the use and benefits of salt as a medium for health supplements and health promotion by taking part in panels about this subject under the auspices of the Journées Nationales de la Diététique in 1991, and of the Entretiens de Bichat (a training event for general medical practitioners) in 1994. In 1990 in partnership with the Union Française pour la Santé Bucco-dentaire (French union for oral hygiene) the French government organised a large-scale publicity campaign, stressing the benefits of fluoride supplements in salt. The campaign distributed 100,000 posters with the slogan 'change your salt' to dentists for display in their waiting rooms, together with several 100,000 leaflets.

From the mid-1990s, the Comite collaborated with the United Nations International Children's Fund (UNICEF) in a campaign for the universal iodisation of salt, aimed mainly at southern-hemisphere countries. Salins' marketing department initially developed this initiative with with the Centre International de l'Enfance (international childhood centre), and then with UNICEF. In 1995, the following text was printed on the side of 'La Baleine ${ }^{\mathrm{TM}}$ 's salt dispensers:

La Baleine, sea salt and our children's growth. LA BALEINE sea salt does more than add flavour to food. With its unique know-how and high technology, LA BALEINE sea salt optimises our intake of iodine - an element which is vital to children's growth - and provides the fluoride which is needed to prevent tooth decay.

Protecting what is most fragile: childhood. In many countries, children are not lucky enough to have an available source of iodine and fluoride. Which is why LA BALEINE sea salt is working with the Centre International de l'Enfance (CIE - international childhood centre) whose aim is to sustainably improve the health and development of children throughout the world. ('La Baleine partenaire...', 1995)

The salt with iodine and fluoride supplements enabled the Comité and its members to promote themselves as acting in the public interest and to reverse salt's negative image by linking it to a virtuous cause, that of helping vulnerable children in the southern hemisphere. At the same time, Salins has become involved in activities designed to protect the environment.

With such strategies, the Comite and Salins were trying not just to promote the benefits of salt and their sense of responsibility, but also to make people forget the negative aspects of salt - in other words, to create diversions. These diversion tactics served as ways of reassuring consumers about the benefits of eating salt. As the Comité's general manager noted with satisfaction in 1993, 'as a medium for iodine and fluoride, salt offers a reassuring image' (CSF, 1993). Such diversion strategies served to build a façade of respectability, which helped conceal the manufacturers'self-interest and the potentially harmful nature of salt consumption. Such diversionary strategies were a form of dissimulation.

\section{Udermining and intimidating opponents}

From 2000, salt was again the subject of criticism by public health and nutritional experts who highlighted the 'hidden salt content' of foods and salt's role in cardiovascular disease and mortality. These experts also contested the Comité and its 
members claims that salt contributed to health. They accused the Comite of misinforming French people about salt's adverse effects on health, and of influencing official nutritional advice on salt consumption.

Faced with such criticism, the Comité continued to use its existing range of countermeasures to defend salt but also mobilised new strategies designed to undermine and intimidate its opponents. It used stigma reversal strategies, that is strategies which consisted in denying the stigma and deflecting back onto those who were trying to attach it to the salt manufacturers. The Comite asserted that the scandal did not lie in 'hidden salt' and in lobbying by the salt industry, but in the unfounded accusations made against salt manufacturers. The Comite accused those trying to stigmatise salt as dangerous - researchers, journalists, and consumer associations - conspiring in an 'antisalt lobby'. The Comité argued that this lobby selected only research and experts who supported their anti-salt cause and that any consensus over the harmful nature of salt was illusionary. For example the Comité's general manager in a letter to the French Director General for Health in 2003 stated that :

The purpose of the conference organised in January 2002 [ the Salt and Health conference organised by French Food Safety Agency], attended by a majority of reductionist experts (including members of the CASH group [a group established by British researchers in 1996 to campaign for a reduction in the amount of salt in processed foods - Consensus Action on Salt \& Health]), was to create the impression of a consensus by keeping away experts who were more cautious about the opportunity for a universal reduction in sodium intake.

The Comité was accusing its opponents of using the practices which they accused the Comité of using. The Comité was willing to make such allegation not only about the collective action of its critics but also of individual critics. Such individual and personal attacks were evident in the Comité's focus on Pierre Meneton, a researcher from the French National Institute of Health and Medical Research who had a high media profile and who was critical of agrifood industries. The attacks came in three forms. In their press releases the Comité questioned Meneton's competency and impartiality. They attempted to silence him by complaining to his superiors. In March 2001, the Comité's general manager sent a thick file to the Institute's managing director to draw his attention to Meneton's 'wild anti-salt imaginings'. Sending managing director a reminder of the fact that the Comite had helped to fund the Institute's research, the Comités general manager asked him whether the institute had 'a disciplinary committee which might reprimand' Meneton. In April 2006, following publication of another interview with Meneton in a news magazine, the Comité's general manager again wrote to the Institute's managing director, asking him 'to impose appropriate sanctions on this extravagant researcher'.

When these demands were not met, the Comité opted for another approach , using his latest interview a defamatory and suing Meneton in court. The Comite also joined up with Salins' French subsidiary to bring civil proceedings against the director and a journalist of the magazine, for having illustrated the interview with a reproduction of a La Baleine ${ }^{\mathrm{TM}}$ salt box with a label similar to those found on cigarette packets stating that 'salt kills'. According to the plaintiffs, the interview and its accompanying illustration amounted to the assertion that salt producers had tried to hide the fact that 
salt was a deadly poison, like tobacco, which was defamatory and untrue. However Meneton successfully defended himself in court using Comité documents to show similarities between the Comité's public relations strategies and those used by tobacco companies.

\section{Discussion}

The strategies used by the Comité to defend a positive image of salt and to undermine official dietary advice are similar to those used by other organisations facing with similar challenges. As Meneton successfully argued in court the defensive activities of the Comite were similar to those used by the tobacco companies to defend their interests. In his study of US tobacco companies, Proctor (2011) describes in great detail strategies of denial and diversion similar to those that I have analysed here. Markowitz and Rosner (2002, p. 64-107) have shown how certain chemical companies work to produce reassuring images of their products, for example by linking them to the medical world or to young children. In the same fashion, Ferreira has noted that 'dispelling consumers' risk perceptions is primarily attempted by means of directing attention to certain contexts, and hence, placing others at the edge or in opposition' (Ferreira, 2006, p. 857). Other studies, for example by Sismondo (2011) on the pharmaceutical industry, have highlighted the 'corporate disguises' of certain manufacturers and their use of 'key opinion leaders' to promote their products. Whilst the Comité's strategies were not exact replicas of those used by these organisations, and their financial resources were far more limited, those used by the Comite are not dissimilar. When manufacturers are trying to defend their reputation or that of their products, in terms of health or environmental risk, everything takes place as if there were not an infinite number of ways of achieving this, but rather a pre-established set of tools and modes of action that these organisations or companies can use.

Using Tilly's (1978) study of collective action, I would argue that this preestablished set of modes of action constitutes a repertoire of collective action. For Tilly, the notion of a repertoire of collective action implies a relative stability in the modes of action that are used by a given category of actors to defend an interest or a cause:

collective action usually takes well-defined forms already familiar to the participants, in the same sense that most of an era's art takes on of a small number of established forms. (Tilly, 1978, p. 143)

For manufacturers, the range of actions available to them to promote a positive image of their products or to create confusion is always very limited, whatever resources they have. They do not systematically invent new forms of action, though this does not exclude, from time to time, innovations or adaptations which might lead to a gradual change in the repertoire content.

The existence of a repertoire of action available to organisations who are trying to defend their reputation or that of their products implies there is some circulation of information about this repertoire. Such circulation is probably helped by factors relating to the morphology of companies and associations of manufacturers, such as the multiple activity or internationalisation of firms, cross-shareholdings, or the existence of closely entwined multi-sector and/or transnational employer organisations. The Comité and its members are not isolated. Since the beginning of the 1980s the Comite has maintained regular relations with counterparts in other European countries, within the framework of 
a joint organisation founded in 1957, and also with the Salt Institute - the association of North-American salt producers. Similarly, Salins was owned by the American group Morton between 1996 and 2006, and Solvay, one of the world's leading chemical groups, has subsidiaries in other countries. These elements encourage the executives of large companies and employer organisations to maintain sociability networks beyond sectorial or national frameworks, thus promoting the circulation of knowledge and know-how (for example, since 1962 the Salt Institute has organised international symposia' on salt, bringing together researchers from academic institutions and corporate executives). The same is true of the many national and international advisory bodies, home to manufacturers' numerous representatives, especially in relation to environmental and health risks (Boudia \& Jas, 2014). Finally, consultants and communication agencies - widely used by manufacturers and employer organisations probably play a major role in the circulation of public relations know-how and practices. Oreskes and Conway (2012) have recently substantiated this point by showing that in the United States, manufacturers from different sectors have often used the same communication agencies and the same experts on matters as diverse as tobacco, acid rain, the ozone hole and global warming.

It is common for manufacturers and employers' associations to use strategies designed to minimise or divert the public's attention away from certain risks. These strategies are part of everyday practices. The findings in this article support my intial argument that the social amplification of risk framework must be modified so as to take better account of participants' strategies, and to ensure that greater attention is paid to the practices of minimising or concealing certain risks.

\section{Conclusion}

In this article I have identified and described some of the principal strategies employed by manufacturers or their associations to defend the image of certain products when their health or environmental safety is challenged. There are certainly activities which were not evident in the case studied here, such as the displacement activities identified by Rayner, which consist in substituting:

management of a representation of a problem [...] for a management of the represented object or activity. (Rayner, 2012, p. 113)

My aim in this article was not to identify all possible strategies, a task which would require a different type of research, but rather to show how such strategies could be simultaneously used by a single organisation, and to what extent they are part of the same repertoire of collective action into which other actors can delve. In this sense, the Comité was helping, at its own level, to update and perpetuate this repertoire.

I found through my analysis that some of the strategies are probably more effective than others. Diversion strategies are also evident in food marketing practices, and more particularly in packaging. As Cochoy clearly noted, packaging plays the dual role of projection and occultation since it prevents any direct access to the products and is a medium of displaying information controlled by the producers (Cochoy, 2002; Cochoy $\&$ Grandclément-Jaffy, 2005). Despite ever more detailed regulations defining the content and form of the information which must appear on packaging, manufacturers systematically manage to highlight some of their products' attributes whilst concealing 
others. We can therefore support the hypothesis that whilst diversion strategies are not as spectacular as direct attacks on scientists, they are far more widespread and are probably more effective: in helping to disseminate contradictory messages into the public space, they probably make a far greater contribution to concealing or minimising certain environmental or health risks.

The example of the Comite is exemplary in the sense that it is a very small organisation. This suggests that even with very limited resources, many manufacturers' associations are in a position to accomplish the work that the Comite has been doing since the beginning of the 1980s. There are dozens of such 'micro-organisations' in the agrifood sector. The multiple messages disseminated by these organisations are certainly not entirely foreign to the coexistence of multiple and contradictory requirements in the public space. This 'nutritional cacophony' (Fischler, 1990), which nutritionists regularly lament, nevertheless constitutes one of the latter's preferred arguments for rejecting any nutritional policy which appears to be too proactive.

I have shown in this article the extent to which the seeds of confusion are sown by certain economic actors and employers' organisations in relation to food-related risks. I have argued that the objectification of these practices of minimizing or deliberately concealing risks is a challenge which is at least as important for the social study of risk as the analysis of processes of social risk amplification.

\section{References}

Allen, B. (2003). Uneasy alchemy: Citizens and experts in Louisiana's chemical corridor dispute. Cambridge, MA: The MIT Press.

Auyero, J., Swistun, D. (2008). The social production of toxic uncertainty. American Sociological Review 73, 357-379.

Auyero, J., Swistun, D. (2009). Flammable: Environmental suffering in an Argentine shantytown. New York: Oxford University Press.

Bachrach, P., Baratz, M. S. (1962). Two faces of power. American Political Science Review 56, 947-952.

Berlivet, L. (2005). Uneasy prevention: The problematic modernization of health education in France after 1975. In V. Berridge \& K. Loughlin (Eds.), Medicine, the market and mass Media: Producing health in the twentieth century (pp. 95-122). London: Routledge.

Blum., E. D. (2008). Love Canal revisited: Race, class, and gender in environmental activism. Lawrence University: Press of Kansas.

Boudia, S., Jas., N. (Eds.) (2014). Powerless science? Science and politics in a toxic world. New York: Berghahn Books.

British Sociological Association (2002). Statement of ethical practice for the British Sociological Association. Retrieved from http://www.britsoc.co.uk/about/equality.aspx.

Burgess, A. (2006). The making of the risk-centred society and the limits of social risk research. Health, Risk \& Society 8, 329-42.

Busby, J. S., Alcock, R.E, MacGillivray, B. H. (2009). Interrupting the social amplification of risk process: A case study in collective emissions reduction. Environmental Science \& Policy 12, 297-308.

CFES (1981). Présentation de la campagne 'Santé et plaisir de la table' [Presentation of the campaign 'Health and pleasure in eating']. Press Conference. Paris: CFES.

Cochoy, F., Grandclément-Chaffy, C. (2005). Publicizing goldilocks' choice at the supermarket: The political work of shopping packs, carts and talk. In B. Latour \& P. Weibel (Eds.), Making things public. Atmospheres of democracy (pp. 646-659). Cambridge, MA/Karlsruhe: The MIT Press/ZKM.

Cochoy., F. (2002). Sociologie du packaging ou l'âne de Buridan face au marché [A sociology of packaging or Buridan's ass faces the market]. Paris: Presses universitaires de France.

Colas., A. (1985). Le sel [Salt]. Paris: Presses universitaires de France. 
Crozier, M., Friedberg, E. (1980). Actors and systems: The politics of collective action, Chicago: University of Chicago Press.

CRUS (1987). Le sel alimentaire [Dietary Salt]. Cahiers de nutrition et de diététique 22, 270-271.

CSF (1985). Rapport du délégué général [Report of the general manager]. Paris: CSF.

CSF (1986). Rapport du délégué général. Paris: CSF.

CSF (1991). Rapport du délégué général. Paris: CSF.

CSF (1993). Rapport du délégué général. Paris: CSF.

CSF (2009). Editorial. Sel \& Nutrition 4, 1.

Douglas, M. (1966). Purity and danger: An analysis of concepts of pollution and taboo. London: Routledge.

Douglas, M. (1986). How institutions think. Syracuse, NY: Syracuse University Press.

Evans-Pritchard, E. E. (1940). The Nuer. Oxford: Clarendon Press.

Ferreira, C. (2006). Food information environments: Risk communication and advertising imagery. Journal of Risk Research 9, 851-68.

Fischler, C. (1990). L'homnivore. Le goût, la cuisine et le corps [The Omnivore: Taste, cooking and the body]. Paris: Odile Jacob.

Frickel, S, Vincent, M. B. (2007). Hurricane Katrina, contamination, and the unintended organization of ignorance. Technology in Society 29, 181-188.

Frickel, S., Edwards, M. (2014). Untangling ignorance in environmental risk assessment. In S. Boudia \& N. Jas (Eds), Powerless science? Science and politics in a toxic world (pp. 215-233). New York: Berghahn Books.

Frickel, S., Gibbon, S., Howard, J., Kempner, J., Ottinger, G., Hess, D. J. (2010). Undone science: Charting social movement and civil society challenges to research agenda setting. Science, Technology \& Human Values 35, 444-473.

Frickel, S., Moore, K. (Eds.). (2006). The new political sociology of science: Institutions, networks, and power. Madison, WI: University of Wisconsin Press.

Gilbert, C., Henry, E. (2012). Defining social problems: Tensions between discreet compromise and publicity. Revue française de sociologie 53 (1), 31-54.

Glaser, B. G., Strauss, A. L. (1967). The discovery of grounded theory. New York: Aldine Publishing Company.

Henderson, J., Wilson A., Meyer, S. B., Coveney, J., Calnan, M., McCullum, D., Lloyd, S., Ward, P. R. (2014). The role of the media in the construction and presentation of food risks. Health, Risk \& Society $16,615-30$.

Henry, E.. 2005. Militer pour le statu quo [Fighting for the status quo]. Politix 70, 29-50.

Hess, D. J. (2007). Alternative pathways in science and industry: Activism, innovation, and the environment in an era of globalization. Cambridge, MA: The MIT Press.

Hilgartner, S. (2000). Science on stage: Expert advice as public drama. Stanford, CA: Stanford University Press.

Kasperson, R. E., Kasperson, J. X. (1996). The social amplification and attenuation of risk. Annals of the American Academy of Political and Social Science 545, 95-105.

Kasperson, R. E., Renn, O., Slovic, P., Brown, H. S., Emel, J., Goble, R., Kasperson, J X., Ratick, S. (1988). The social amplification of risk: A conceptual framework. Risk Analysis 8, 177-187.

Kleinman, D. L., Suryanarayanan, S. (2013). Dying bees and the social production of ignorance. Science, Technology \& Human Values 38, 492-517.

La Baleine partenaire du Centre international de l'enfance [La Baleine, partner of the International Childhood Centre] (1995, December). Le Salinier, 3.

Markowitz, G., Rosner, D. (2002). Deceit and denial: The deadly politics of industrial pollution. Berkeley, CA: University of California Press.

McCulloch, J., Tweedale, G. (2008). Defending the indefensible: The global asbestos industry and its fight for survival, Oxford: Oxford University Press. 
McGoey, L. (2012). The logic of strategic ignorance. The British Journal of Sociology 63, 553-576.

Michaels, D. (2008). Doubt is their product: How industry's assault on science threatens your health. Oxford: Oxford University Press.

Moinier, B. (1997). Sel et société [Salt and society]. Paris: Nathan.

Moinier, B. (1990). Le sel fluoré: de la production à la consommation [Fluoridated salt: From consumption to production]. Cahiers de nutrition et de diététique 25, 273-276.

Moores, S. (1993). Interpreting audiences: The ethnography of media consumption. London: Sage.

Oreskes, N., Conway, E. M. (2010). Merchants of doubt: How a handful of scientists obscured the truth on issues from tobacco smoke to global warming. New York: Bloomsbury.

Proctor, R. N. (2008). Agnotology: A missing term to describe the cultural production of ignorance (and its study). In R. N. Proctor \& L. Schiebinger (Eds.), Agnotology: The making \& unmaking of ignorance, (pp. 1-36). Stanford, CA: Stanford University Press.

Proctor, R. N. (2011). Golden holocaust: Origins of the cigarette catastrophe and the case for abolition. Berkeley: University of California Press..

Ragin, C. C., Becker, H. S. (Eds). (1992). What is a case? Exploring the foundations of social inquiry Cambridge, MA: Cambridge University Press.

Rayner, S. (1988). Muddling through metaphors to maturity: A commentary on Kasperson et al., The social amplification of risk. Risk Analysis 8, 201-204.

Rayner, S. (2012). Uncomfortable knowledge: The social construction of ignorance in science and environmental policy discourses. Economy and Society 41, 107-25.

Renn, O. (2011). The Social Amplification/attenuation of Risk Framework: Application to climate change. WIREs Climate Change 2, 154-69.

Ross, B., Amter, S. (2010). The Polluters: The making of our chemically altered environment. Oxford: Oxford University Press.

Sismondo, S. (2011). Corporate disguises in medical science: Dodging the interest repertoire. Bulletin of Science, Technology \& Society 31, 482-92.

Tilly, C. (1978). From mobilization to revolution. New York: Random House.

Torny, D. (2005). Food risk facing consumers. INRA Sciences Sociales. Research in Economics and Rural Sociology 20, 1-4.

Vaughan, D. 1999. The dark side of organizations: Mistake, misconduct, and disaster. Annual Review of Sociology 25, 271-305.

Vogel, S. (2012). Is it safe? BPA and the struggle to define the safety of chemicals. Berkeley, CA: University of California Press.

Yin, R. K. (2013). Case study research: Design and methods (5th ed.). Los Angeles: Sage.

Zinn, J. O. (2015). Towards a better understanding of risk taking: Key concepts, dimensions and perspectives, Health, Risk \& Society XXXX 